\title{
Epstein-Barr Virus-Negative Lymphoproliferative Disorders after Liver Transplantation
}

\author{
Mitsugi Shimoda*, Junji Kita, Masato Kato, Tokihiko Sawada and Keiichi Kubota
}

Department of Gastroenterological Surgery, Dokkyo Medical University School of Medicine, 880 Kitakobayashi, Mibu, Tochigi 321-0293, Japan

\begin{abstract}
Lymphoproliferative disorders following liver transplantation are often Epstein-Barr virus (EBV)-related highgrade B cell lymphomas. EBV-negative and low-grade lymphoma is a very rare condition after cadaveric as well as living donor liver transplantation (LDLT). Herein we report a case of follicular lymphoma with negative EBV viral capsid antigen (VCA), IgM, IgG and Epstein-Barr virus-encoded small RNA (EBER), which developed after LDLT, and review the literature pertaining to EBV-negative post-transplantation lymphoproliferative disorder (PTLD) after liver transplantation.
\end{abstract}

Key Words: Follicular lymphoma, living donor liver transplantation, positron emission tomography with computed tomography, Epstein-Barr virus, lymphoproliferative disorders.

\section{INTRODUCTION}

Among lymphomas that develop after transplantation, post-transplantation lymphoproliferative disorder (PTLD) is well known. PTLD is mostly of B-cell origin and is often associated with active infection by Epstein-Barr virus (EBV), an oncogenic herpes virus observed in most patients with PTLD. With the rise in the number of patients undergoing organ transplantation, the incidence of PTLD has also increased, with a reported incidence of $2-4 \%$ and a mortality exceeding $50 \%$ [1]. The etiology of this disease varies depending on the extent of immunosuppression and the type of organ transplanted. Heart, liver, lung, and intestine allografts are at greater risk for PTLD than renal allografts. Also, primary EBV infection in young solid-organ transplant patients and treatment with cyclosporine are risk factors for PTLD development. As many as $90 \%$ of all PTLD cases are triggered by primary EBV. EBV infection occurring in the first 3-5 months after transplantation in patients with pretransplant seronegativity for EBV infection is a risk factor for development of PTLD.

Although the majority of lymphomas developing after solid organ transplantation are EBV-associated, high-grade, B-lineage lymphoid neoplasms, a recent increase in EBVnegative PTLD has been noted $[1,2]$. Most cases of PTLD occurring after organ transplantation belong to the polymorphic and diffuse large B-cell type that is related to EBV. Low-grade B-cell lymphomas, such as follicular lymphoma, are very rare [3].

With the aim of characterizing the clinical features and outcomes of non-EBV-related low-grade B-cell lymphoma after liver transplantation (LT), we report a case encountered

*Address correspondence to this author at the Department of Gastroenterological Surgery, Dokkyo University School of Medicine, 880 Kitakobayashi, Mibu, Tochigi 321-0293, Japan; Tel: +81-282-87-2158; Fax: +81282-86-6317; E-mail: mshimoda@dokkyomed.ac.jp at our department, and review the literature pertaining to all reported cases of this type of neoplasm. No cases in living donor liver transplantation (LDLT) recipients have been identified up to now.

\section{CASE REPORT}

Under a diagnosis of primary biliary cirrhosis, a 60-yearold woman underwent LDLT (left lobe graft) in February 2002. On the 23rd postoperative day, she developed tacrolimus-induced encephalopathy and the immunosuppressive agent was therefore switched to CsA (Neoral; Novartis, Basel, Switzerland). Her recent medical record indicated that abdominal CT conducted in October 2004 had demonstrated swollen lymph nodes around the upper abdominal aorta. Positron emission tomography with computed tomography (PET/CT) showed marked accumulation of the radionuclide at the para-aortic lymph nodes in the upper abdomen (Fig. 1). The blood soluble IL2 receptor content had increased to $659 \mathrm{U} / \mathrm{ml}$ (normal: 135 to $483 \mathrm{U} / \mathrm{ml}$, Fig. 2), suggesting the

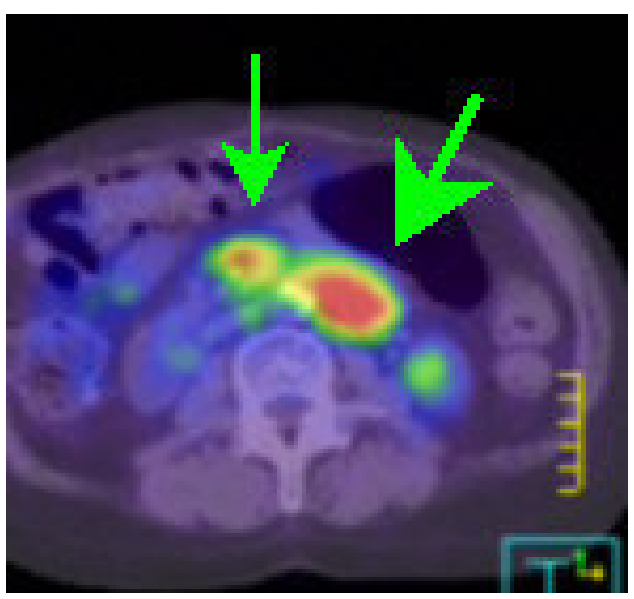

Fig. (1). PET/CT shows a marked hot spot at the para-aortic lymph nodes in the upper abdomen (arrows). 


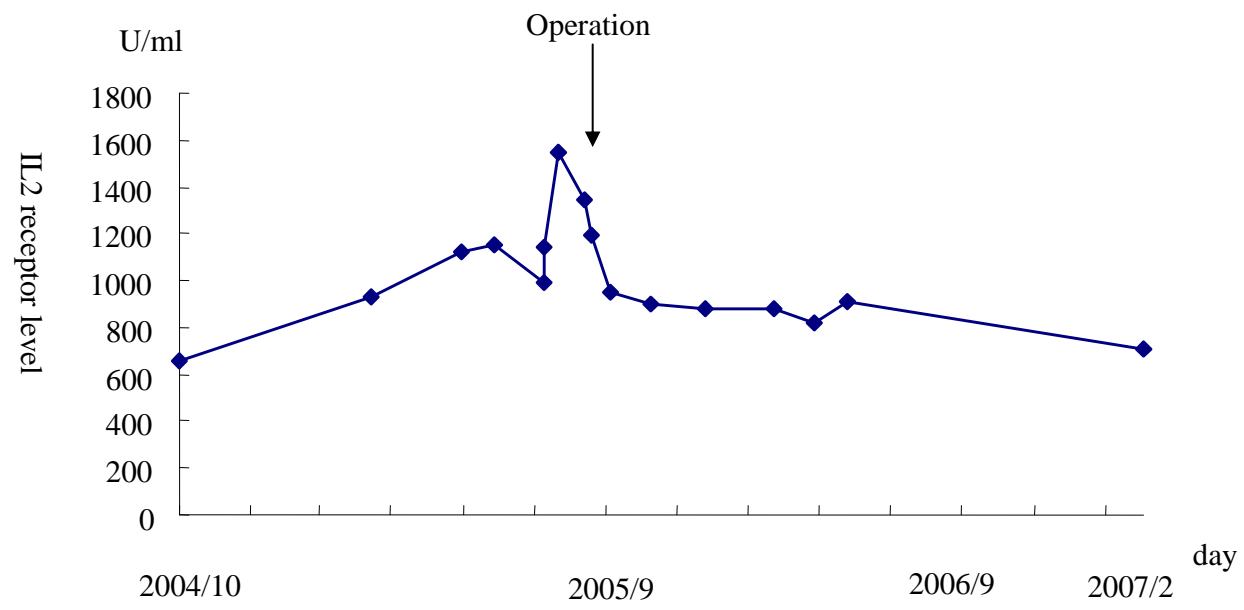

Fig. (2). Alteration of serum IL2 levels after detection of abdominal lymph node swelling.

presence of a malignant lymphoma. The patient showed negativity for EBV VCA, IgM, and IgG before transplantation and positivity for those parameters $(\times 160)$ after. Similar results were also obtained from the donor. The dosage of Neoral (120 mg to $80 \mathrm{mg}$ ) was reduced to give a blood concentration of less than $100 \mathrm{ng} / \mathrm{ml}$, and steroid (Medrol $4 \mathrm{mg}$ ) administration was discontinued. The IL2 receptor level was determined and PET/CT was conducted periodically while the patient was placed under observation. Although the tumor did not seem to increase in size, the soluble IL2 receptor level rose to $1,350 \mathrm{U} / \mathrm{ml}$. Patient lowest white cell count was $3.50 \times 109 / 1$ pre LDLT. Post LDLT level of white cells was range 7.0 to $8.0 \times 109 / 1$ until time of lymph node development. There was not differential white cell counts time of LDLT, post LDLT and lymph node development. Tumor extirpation was contemplated, but the patient developed cholangitis due to choledocholithiasis in September 2005. In October, she underwent choledocholithotomy with T-tube drainage and para-aortic lymph node resection (Fig. 3). An immunohistological examination showed that the lymph nodes had been affected by a low-grade follicular lymphoma (Fig. 4a, b and c). However, Epstein-Barr virus-encoded small RNA (EBER) was negative (Fig. 5). One year after the operation, no hot spot was evident in the abdomen by PET/CT and the soluble IL2 receptor level was reduced to $706 \mathrm{U} / \mathrm{ml}$. For postoperative adjuvant therapy, administration of rituximab (MabtheraR, Hoffman-La Roche AG, Grenzach-Whylen, Germany) was considered but rejected because the lymphoma was of low-grade malignancy and the patient did not wish to undergo this mode of chemotherapy. She is currently under observation.

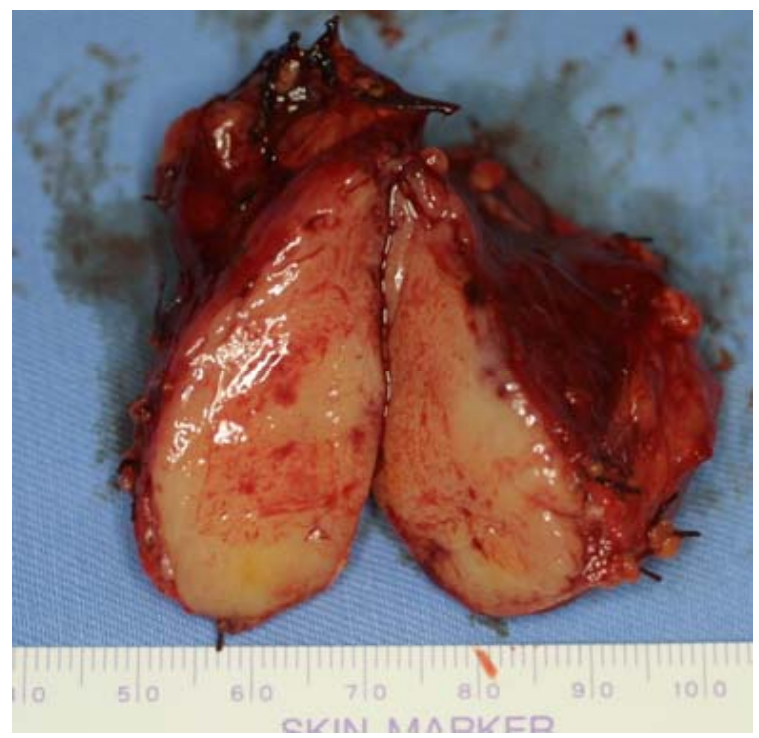

Fig. (3). A resected lymph node, appearing soft, with a smooth and white cut surface.

\section{LITERATURE REVIEW}

A medline search was conducted to identify reported cases of EBV-negative PTLD in liver transplant patients a

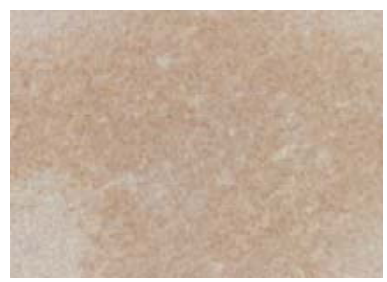

CD10 positive b

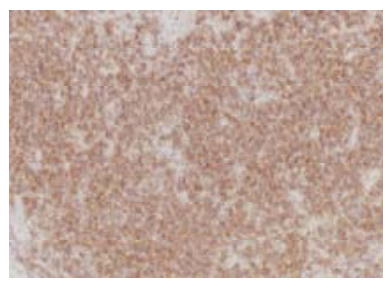

CD20 positive c

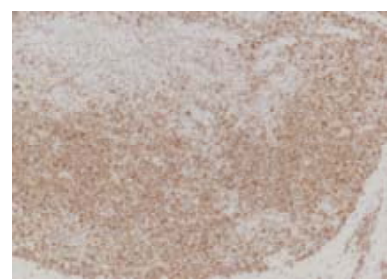

BCL-2 positive

Fig. (4). CD 10 (a), CD 20 (b) and BCL-2 (c) are all positive immunohistologically. 
from January 1963 to August 31, 2007 using, "EBV-negative" and "liver transplant" as index terms. A secondary search was performed to include references cited in the articles obtained by the initial search. Recently diagnosis of EBV infection has been made by EBER in situ hybridization (ISH) [4],

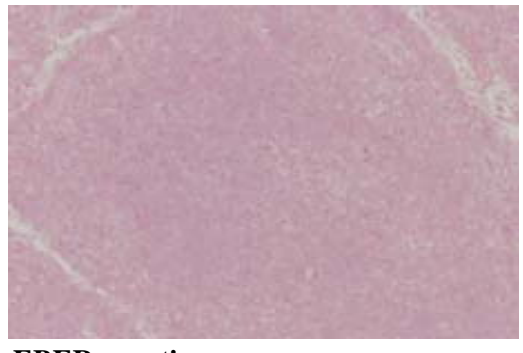

EBER negative

Fig. (5). EBER is negative histologically.

reported 22 cases of PTLD after LT, 8 of which were EBERnegative. Only one of the 8 cases were diagnosed as follicular lymphoma by histology [5], reported an interesting study of 133 cases of PTLD after organ transplants. Seventeen of these cases were EBER-negative, and all of them were observed after 1990, whereas one half of the 133 cases observed before 1990 were EBER- positive. Furthermore, none of the 17 EBER-negative PTLD cases that developed after LT was follicular lymphoma. The Pittsburgh [6] group reported 104 cases of PTLD after LT, 80\% of which were EBER-positive, whereas EBER was not detected in the other $20 \%$. Unfortunately, this report did not document whether any cases of follicular lymphoma were included. In another large series of PTLD occurring after LT, 11 of 37 PTLDs were negative for EBER, and histological diagnoses revealed that all of these cases were monomorphic-type lymphoma [1] reported 16 cases of PTLD after LT, 4 of which were EBERnegative, and the histological diagnosis was diffuse large Bcell-type lymphoma in all cases [3] also reported a case of post-LT follicular lymphoma. Our review revealed a total of 51 cases of EBER-negative PTLD, but only 2 of them were EBER-negative follicular lymphoma. Moreover, both of these cases occurred after cadaveric LT, and not after 'LDLT'.

\section{DISCUSSION}

Follicular lymphoma occurs in only $3-10 \%$ of patients with non-Hodgkin's lymphoma, the incidence being particularly high in Europe and North America, and its incidence as a complication of EBV infection is somewhat rare [7,8]. As a rule, the original site of involvement is the lymph nodes, and extra-nodal areas affected include the spleen, bone marrow and duodenum [9]. Histologically, it is a malignant B cell tumor that originates from B cells, exhibiting a characteristic follicular structure. It has been said that the percentage of large non-cleaved cells that resemble centroblasts within the tumorous follicles has a bearing on the prognosis. According to the WHO classification, these tumors are graded as 1,2 or 3 by counting the large non-cleaved cells in the tumorous follicles. Specifically, 10 tumorous follicles are examined in a field at $\times 40$ magnification and large non-cleaved cells are counted: if there are fewer than 5, the condition is graded as 1 , if 6 to 15 as 2, and if over 16 as 3[10]. The characteristic immunohistochemical markers are positive B cell markers (CD19, CD20, CD22 and CD79) and BCL2- and CD10- positive reactions. It has been said that histological grade 3 indicates a poor prognosis in comparison with grade 1 or 2 . The literature lists two previous cases of follicular lymphoma that developed after liver transplantation [4], but the present case is the first reported to have developed after LDLT.

PTLD is a lymphoma observed after transplantation, and occurs particularly frequently among young children after kidney or heart transplantation [11]. Although various etiological factors have been considered, the use of antilymphocyte antibodies and EBV infection are commonly cited. PTLD develops particularly frequently in EBV-seronegative recipients who have received organs from EBV-seropositive donors. With the recent increase in the frequency of transplantation, PTLD has begun to occur occasionally in EVBnegative patients, the increase amounting to $20 \%$ of this population group. For diagnosis, PTLD is classified morphologically as follows: 1) early lesion; 2) polymorphic PTLD; 3) monomorphic PTLD of diffuse large cell lymphoma or Burkitt-like lymphoma; and 4) T-cell type lymphoma [12]. Furthermore, EBER or the Epstein-Barr virus latent protein (LMP) is used for immunohistological diagnosis [11]. Recently, however, there have been reports of cases such as the present one that do not belong to any of these four categories and are EBER- or LMP-negative. There is no clear-cut diagnostic standard determining whether this B-cell-type lymphoma should be categorized as a common malignant lymphoma or as PTLD.

The treatment of a lymphoma that occurs after transplantation starts with reduction in the dosages of immunosuppressants, and if the patient is EBV-positive, antiviral therapy is instituted. If the lymphoma is aggressive, chemotherapy is added. For the treatment of non-Hodgkin's lymphoma, rituximab, a chimeric monoclonal anti-CD20, recently introduced as a first-line therapy, has proven to be effective [11]. For the present case, postoperative use of rituximab was considered but subsequently rejected because the lymphoma showed low-grade malignancy and the patient refused its use.

To confirm the presence of PTLD, CT or PET has been employed. McCormack et al. reported that PET/CT was effective for localizing PTLD that had developed after liver transplantation. The use of CT simultaneously with PET, in particular, pinpoints the anatomical site of the lesion by radionuclide accumulation. This is considered to be very effective for pinpointing the site of a biopsy [13]. The efficacy of post-transplantation PET/CT is expected to improve further.

\section{REFERENCES}

[1] Duvoux C, Pageaux GP, Vanlemmens C, et al. Risk factors for lymphoproliferative disorders after liver transplantation in adults: an analysis of 480 patients. Transplantation 2002; 74: 1103-9.

[2] Leblond V, Davi F, Charlotte F, et al. Posttransplant lymphoproliferative disorders not associated with Epstein-Barr virus: a distinct entity? J Clin Oncol 1998; 16: 2052-9.

[3] Racz MM, Link BK, Vasef MA. Follicular lymphoma following liver transplantation: report of a unique case with review of the literature. Transplant Proc 2004; 36: 2782-6.

[4] Koch DG, Christiansen L, Lazarchick J, Stuart R, Willner IR Reuben A. Posttransplantation lymphoproliferative disorder--the great mimic in liver transplantation: appraisal of the clinicopathologic spectrum and the role of Epstein-Barr virus. Liver Transpl 2007; 13: 904-12. 
[5] Nelson BP, Nalesnik MA, Bahler DW, Locker J, Fung JJ, Swerdlow SH. Epstein-Barr virus-negative post-transplant lymphoproliferative disorders: a distinct entity? Am J Surg Pathol 2000; 24: 375-85.

[6] Jain A, Nalesnik M, Reyes J, et al. Osttransplant lymphoproliferative disorders in liver transplantation: a 20-year experience. Ann Surg 2002; 236: 429-36.

[7] Banks PM, Chan J, Cleary ML, et al. Mantle cell lymphoma. A proposal for unification of morphologic, immunologic, and molecular data. Am J Surg Pathol 1992; 16: 637-40.

[8] Chan WC, Armitage JO, Gascoyne R, et al. A clinical evaluation of the International Lymphoma Study Group classification of nonHodgkin's lymphoma. Blood 1997; 89: 3909-18.
[9] Solal-Celigny P, Roy P, Colombat P, et al. Follicular lymphoma international prognostic index. Blood 2004; 104: 1258-65.

[10] Jaffe ES, Karris NL, Stein H, et al. World Health Organization Classification of Tumours. Pathology \& Genetics. Tumours of Hematopoietic and Lymphoid Tissues, IARC Press: Lyon 2001.

[11] Leblond V, Choquet S. Lymphoproliferative disorders after liver transplantation. J Hepatol Rev 2004; 40; 728-35.

[12] Harris NL, Ferry JA, Swerdlow SH. Posttransplant lymphoproliferative disorders: summary of Society for Hematopathology Workshop. Semin Diagn Pathol 1997; 14: 8-14.

[13] McCormack L, Hany TI, Hubner M, et al. How useful is PET/CT imaging in the management of post-transplant lymphoproliferative disease after liver transplantation? Am J Transplant 2006; 6: 17316.

(C) Shimoda et al.; Licensee Bentham Open.

This is an open access article licensed under the terms of the Creative Commons Attribution Non-Commercial License (http: //creativecommons.org/licenses/ by-nc/3.0/) which permits unrestricted, non-commercial use, distribution and reproduction in any medium, provided the work is properly cited. 